\title{
Wandering spleen with torsion presenting as a rare case of acute abdomen
}

\author{
Solomon Bekele Abebe ${ }^{\mathrm{a},{ }^{*}}$, Yonas Ademe Teferi ${ }^{\mathrm{a}}$, Henok T/Silassie Zeleke ${ }^{\mathrm{a}}$ \\ ${ }^{a}$ Department of Surgery, Addis Ababa University, College of Health Sciences, Addis Ababa, Ethiopia.
}

\begin{abstract}
Wandering spleen is a rare clinical occurrence characterized by the absence of spleen in its normal anatomic place. Patients may present with acute abdomen, abdominal mass, and chronic abdominal pain. Prompt diagnosis and intervention are necessary. Here, we report a case of a woman who presented with acute abdominal pain secondary to a wandering spleen complicated by torsion of its vascular pedicle.

Keywords: Wandering spleen; torsion; splenectomy
\end{abstract}

\section{INTRODUCTION}

The spleen develops from the mesoderm in the dorsal mesogastrium. It lies in the left hypochondrium behind the stomach, and is approximately $12 \mathrm{~cm}$ long and 7 $\mathrm{cm}$ wide. The spleen is fixed in position by the lienorenal and gastrosplenic ligaments; the phrenicocolic ligament provides additional support. The ligaments are embryological condensations that take place in the peritoneum, and congenital peritoneal anomalies may result in splenic displacement ${ }^{[1,2]}$.

Wandering spleen, also known as displaced, ectopic, drifting, floating spleen, or Solenopsis is a rare condition defined as a huge, single spleen in an abdominal position rather than its anatomical site, owing to laxity of its pedicles and absence of ligamentous attachments [3].

Acquired anomalies have been described and are attributed to laxity of the ligaments due to weakness of the abdominal wall, multiple pregnancies, hormonal changes, or an increase in size in the spleen. Both congenital and acquired conditions result in a long pedicle, which is predisposed to torsion. The splenic vessel's

\footnotetext{
* Corresponding author: Solomon Bekele Abeb

Mailing address: Department of Surgery, Addis Ababa University, College of Health Sciences, Addis Ababa, Ethiopia.

E-mail: solbekeleabebe@gmail.com

Received: 13 May 2021 / Accepted: 08 September 2021
}

course within the pedicle, and therefore, torsion of the pedicle results in partial or complete infarct of the spleen $^{[3,4]}$.

We report a case of torsion of a wandering spleen in a 40 years old multiparous woman who presented to our emergency with an acute abdomen.

\section{CASE REPORT}

A 40 years old female patient presented to our emergency room with abdominal pain and progressive abdominal distention of a two-week duration which got worsen over the past 24 hours. She claims to have 3 episodes of vomiting of ingested matter. She had no prior similar illness nor chronic medical conditions. She is a para 8 mother from rural Ethiopia. Physical examination revealed tachycardia of $100 / \mathrm{min}$. Abdominal examination showed a huge, firm, tender periumbilical mass measuring $12 \times 8 \mathrm{~cm}$ extending to the right lower quadrant area, with positive signs of fluid collection. Abdominal radiography showed an important colon distention especially at the upper left quadrant without air-fluid levels (Figure 1). Abdominal ultrasound is done showed a midline pelvic region solid mass, measuring $12.8 \times 6.3 \times 14.9 \mathrm{~cm}$ in size (Figure 2). There were multiple internal echogenic foci with no distal shadowing, likely micro hemorrhage, and spleen not visualized in its normal anatomic location. Laboratory findings of the patient are shown in Table 1. 
The patient underwent emergency exploratory laparotomy revealed a significantly enlarged, infarcted wandering spleen, located in an ectopic location (Figure 1). Suspended with only its pedicle which was twisted $360^{\circ}$ in counterclockwise direction dragging tail of the pancreas (Figure 2). There were few peritoneal and omental adhesions.

Splenectomy was performed avoiding injury to the pancreatic tail (Figure 3-5). The histology section

Table 1. Laboratory findings of the patient.

\begin{tabular}{ll}
\hline Index & Result \\
\hline WBC & $12,300 / \mathrm{mm}^{3}$ \\
Hemoglobin & $9.5 \mathrm{~g} / \mathrm{dl}$ \\
Hematocrit & $30.1 \%$ \\
Platelet Count & $514,000 / \mathrm{mm}^{3}$ \\
Urea & $13 \mathrm{ng} / \mathrm{dl}$ \\
Creatinine & $0.8 \mathrm{ng} / \mathrm{dl}$ \\
\hline
\end{tabular}

WBC: White Blood Count.

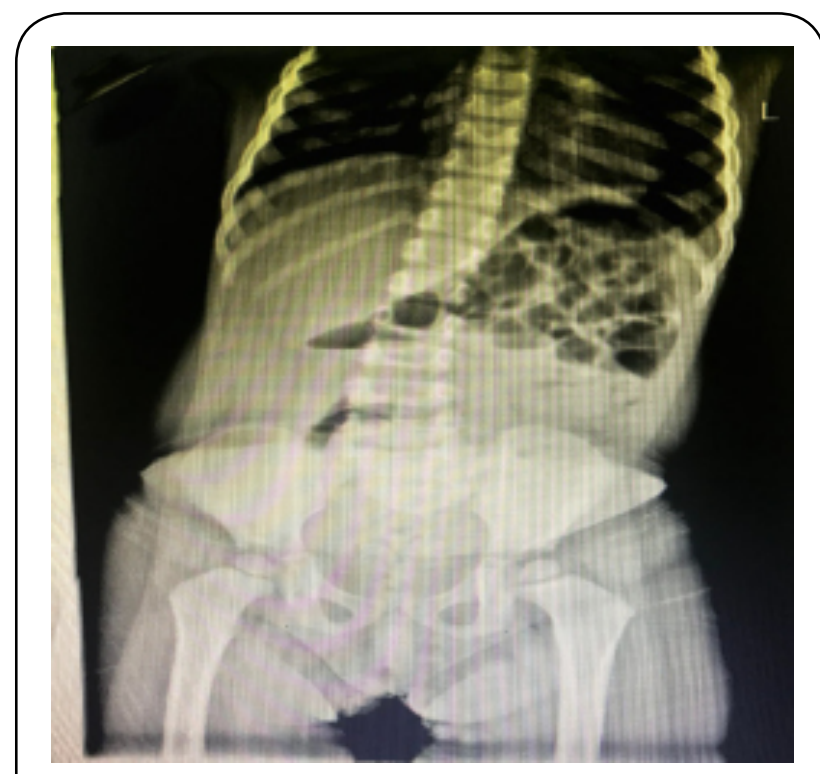

Figure 1. Erect abdominal film. Absence of splenic shadow in the left upper quadrant and hypogastric mass of soft tissue density.

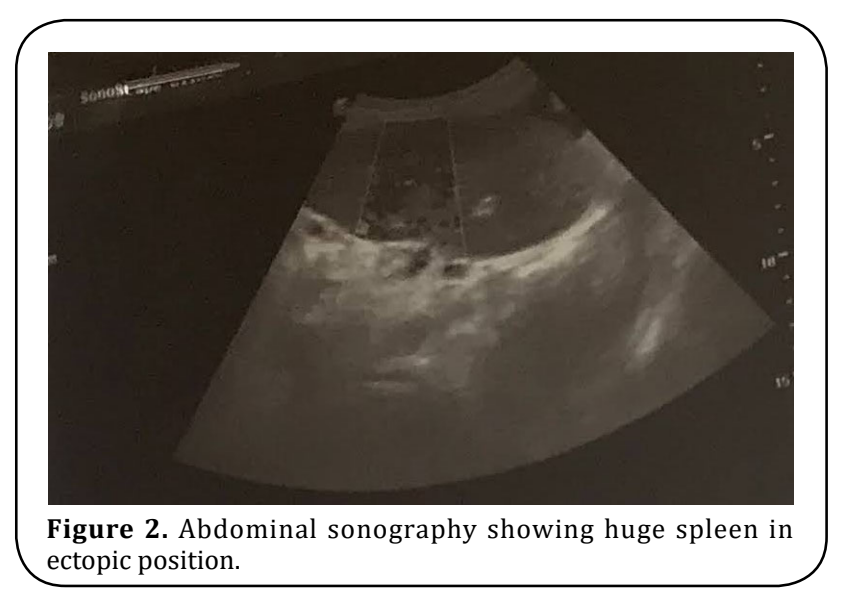

showed tissue mainly composed of hemorrhage, congested blood vessels with lymphocyte, plasma cells, and neutrophils. The features were consistent with splenic infarction of ischemic origin. The postoperative period was uneventful. The patient was discharged on the fourth postoperative day, to come back for vaccination two weeks later.

\section{DISCUSSION}

Wandering spleen is a rare clinical finding where the spleen is found suspended by only its mesentery. It is usually found in young children and women aged between 20 and 40 years of age. Most cases are attributed to be congenital in origin but acquired conditions like multiple pregnancies have also been incriminated. The splenic vessel's course within the pedicle, and therefore, torsion of the pedicle results in a partial or complete infarct of the spleen ${ }^{[5]}$. Torsion of a wandering spleen is diagnosed in about $0.2-0.3 \%$ of patients who require splenectomy. The clinical presentation of the wandering spleen may be variable, from an asymptomatic patient to one with mild abdominal pain, signs of acute abdomen with or without peritonitis ${ }^{[2,}$ ${ }^{6}$. Ultrasound imaging with duplex scanning can be used as an initial mode of imaging which can show the position of the wandering spleen with concomitant replacement of bowel in the left upper quadrant. CT contrast imaging is the preferred mode of investigation, with the contrast helping to elucidate the viability of the spleen. An early diagnosis and surgical care are the best guarantees for preserving the spleen ${ }^{[7]}$ (Table 2).

Table 2. Characteristics of reported cases of wandering spleen.

\begin{tabular}{|c|c|c|c|c|c|}
\hline Case & Age & Gender & $\begin{array}{l}\text { Diagnostic } \\
\text { Modality }\end{array}$ & $\begin{array}{l}\text { Type of } \\
\text { surgery } \\
\text { performed }\end{array}$ & Reference \\
\hline 1 & 36 & Female & CT & Splenectomy & $\begin{array}{l}\text { (Khan et al., } \\
\text { 2018) }\end{array}$ \\
\hline 2 & 32 & Female & $\mathrm{U} / \mathrm{S}$ and $\mathrm{CT}$ & Splenectomy & $\begin{array}{l}\text { (Chauhan } \\
\text { \& Kumar, } \\
2016 \text { ) }\end{array}$ \\
\hline 3 & 24 & Female & $\mathrm{U} / \mathrm{S} / \mathrm{CT}$ & Splenectomy & $\begin{array}{l}\text { (Kafadar et } \\
\text { al., 2021a) }\end{array}$ \\
\hline 4 & 35 & Female & CT & Splenectomy & $\begin{array}{l}\text { (Awan et al., } \\
\text { 2019) }\end{array}$ \\
\hline 5 & 18 & Female & CT & Splenectomy & $\begin{array}{l}\text { (Colombo et } \\
\text { al., 2020a) }\end{array}$ \\
\hline 6 & 13 & Female & $\mathrm{U} / \mathrm{S}$ & Splenectomy & $\begin{array}{l}\text { (Assaf et al., } \\
\text { 2020a) }\end{array}$ \\
\hline 7 & $\begin{array}{l}27 \text { and } \\
20\end{array}$ & Females & CT & Splenectomy & $\begin{array}{l}\text { (Virani et al., } \\
\text { 2021a) }\end{array}$ \\
\hline 8 & 36 & Male & $\mathrm{CT} / \mathrm{MRI}$ & Splenectomy & $\begin{array}{l}\text { (Leci- } \\
\text { Tahiri et al., } \\
\text { 2013a) }\end{array}$ \\
\hline
\end{tabular}




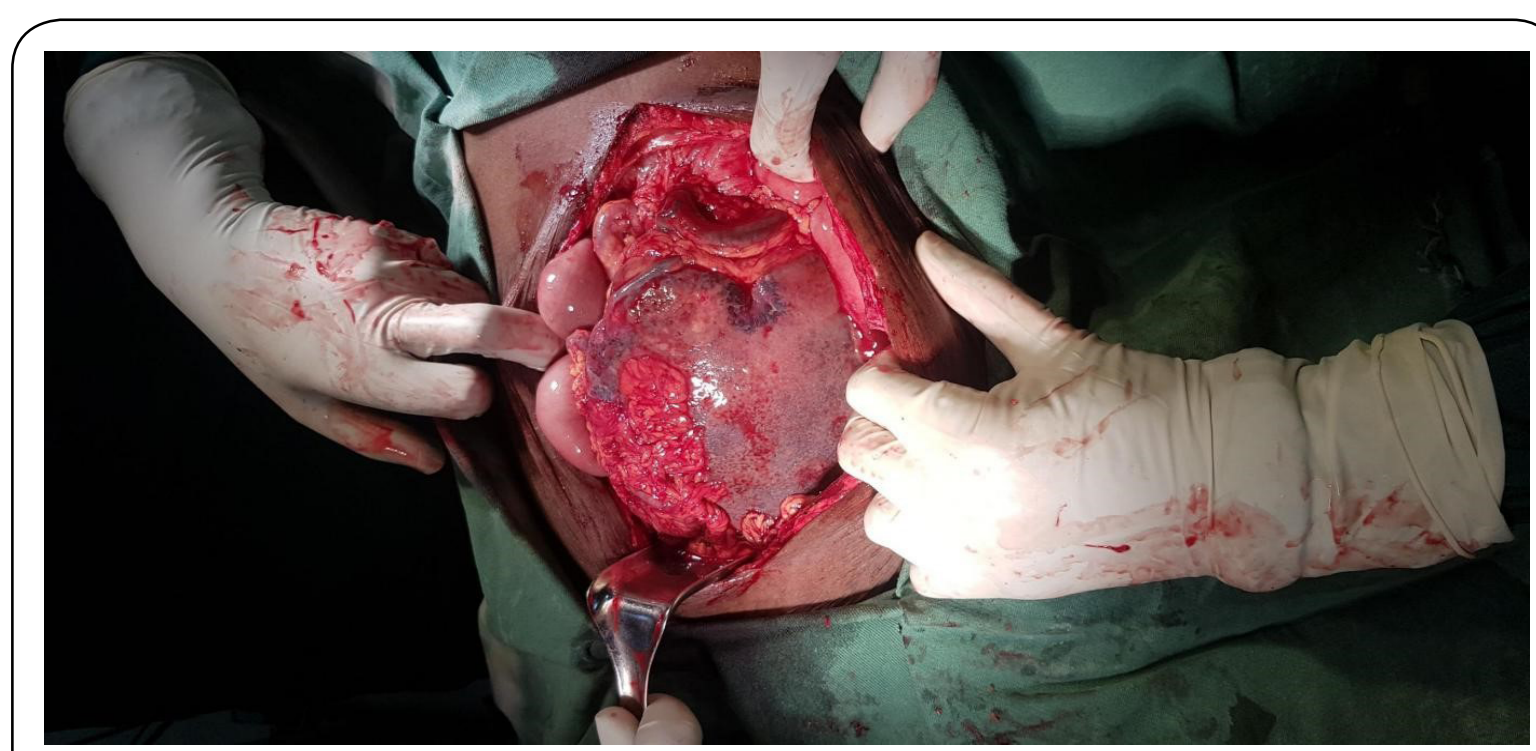

Figure 3. Huge spleen located in the mid abdomen extending to the pelvis.
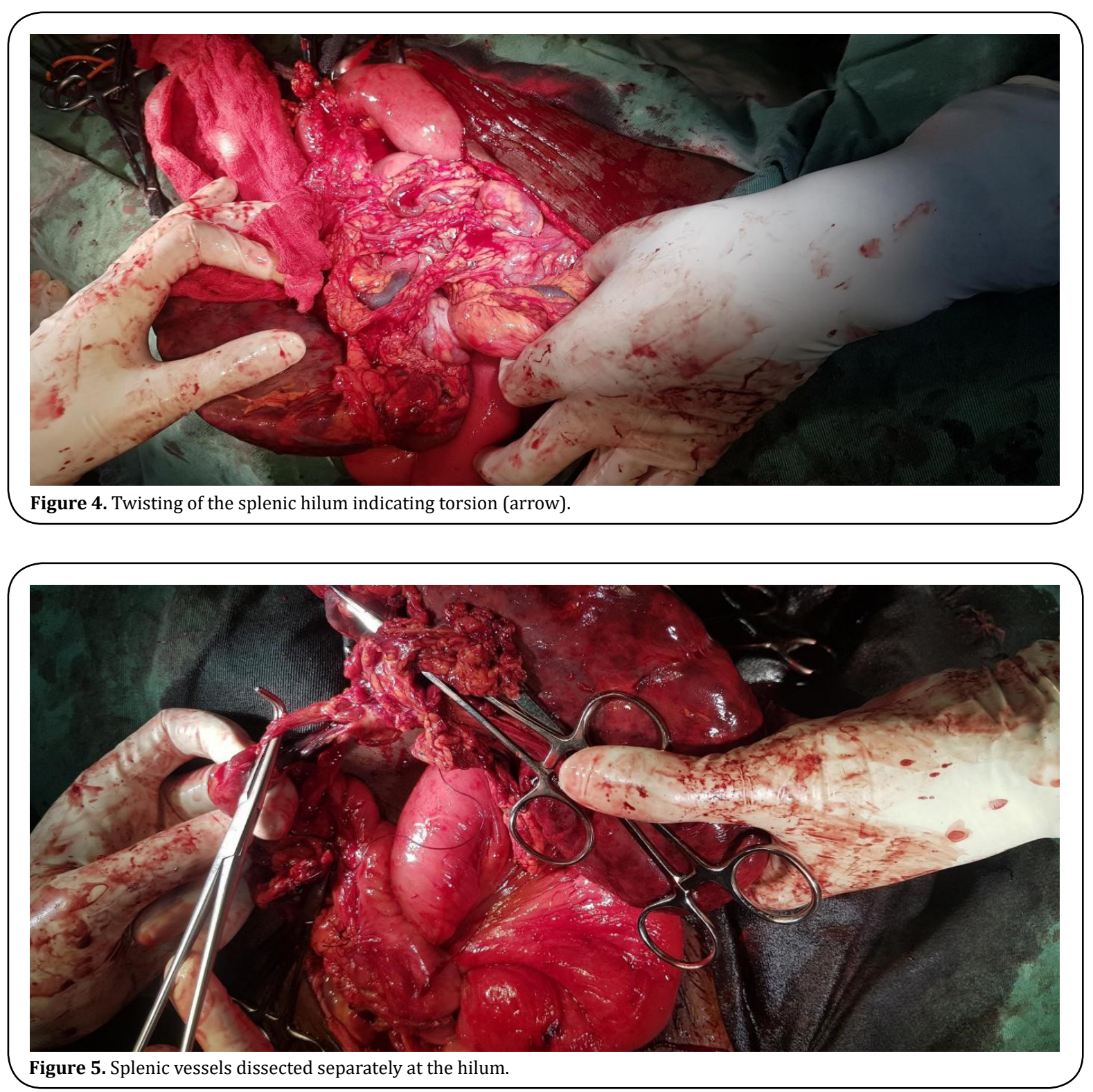
The spleen in our patient was hugely enlarged with the absence of all splenic ligamentous attachments and short gastric vessels with a consequent dislocation of a bigger, congested , and infarcted spleen in the pelvis.

Splenic salvation is always the choice in the case of the non-infarcted spleen, especially in young patients. Anti-Pneumococcal, Hemophilus influenza, and meningococcal vaccines are indicated before elective splenectomy and shortly after non-elective splenectomy ${ }^{[8]}$.

\section{CONCLUSION}

A wandering spleen must be suspected in patients who present with acute abdomen and a palpable mass. Diagnosis requires a high index of clinical suspicion. Abdominal ultrasound and CT are important adjuncts to diagnosis. Splenopexy or splenectomy are options of management depending on whether or not there is infarction.

\section{DECLARATIONS}

\section{Authors' contributions}

Solomon involved in pre-operative preparation, operation, post op follow-up and wrote this article. Henok supervised the surgery and checked the article. Yonas assisted in the surgery and followed patient postoperatively.

\section{Conflicts of interest}

The authors declare that there are no conflicts of interest to disclose.

\section{Ethical approval and consent to participate}

The study, which included human samples, complied with the Declaration of Helsinki and obtained written informed consent from all patients involved.

\section{REFERENCES}

1. Chauhan, N. S., \& Kumar, S. (2016). Torsion of a Wandering Spleen Presenting as Acute Abdomen. Polish Journal of Radiology, 81, 110-113.

2. Khan, D. B., Khandwala, K., Abbasi, S. U., Khan, S. D., \& Raza, R. (2018). Torsion of Wandering Spleen with Infarction. Cureus, 10(8), e3177.

3. Kafadar, M. T., Daduk, Y., \& Karakoç, M. (2021). Acute abdomen due to torsion of the wandering spleen: A rare clinical presentation. Ulusal Travma Veacil Cerrahi Dergisi, 27(1), 154-156.

4. Assaf, R., Shebli, B., Alzahran, A., Rahmeh, A. R., Mansour, A., Hamza, R., ... \& Ayoub, K. (2020). Acute abdomen due to an infarction of wandering spleen: case report. Journal of Surgical Case Reports, 2020(2), rjz378.

5. Virani, P., Farbod, A., Niknam, S., \& Akhgari, A. (2021). Wandering spleen with splenic torsion: Report of two cases. International Journal of Surgery Case Reports, 78, 274-277.

6. Colombo, F., D’Amore, P., Crespi, M., Sampietro, G., \& Foschi, D. (2020). Torsion of wandering spleen involving the pancreatic tail. Annals of Medicine and Surgery, 50, 10-13.

7. Awan, M., Gallego, J. L., Al Hamadi, A., \& Vinod, V. C. (2019). Torsion of wandering spleen treated by laparoscopic splenopexy: A case report.International Journal of Surgery Case Reports, 62, 58-61.

8. Leci-Tahiri, L., Tahiri, A., Bajrami, R., \& Maxhuni, M. (2013). Acute abdomen due to torsion of the wandering spleen in a patient with Marfan Syndrome. World Journal of Emergency Surgery, 8(1), 30. 